\title{
Erratum to: On the Boundedness of Singular Integrals in Morrey Spaces and Its Preduals
}

\author{
Marcel Rosenthal $^{1}$ • Hans-Jürgen Schmeisser ${ }^{1}$
}

Received: 7 October 2015 / Published online: 16 October 2015

(C) Springer Science+Business Media New York 2015

\section{Erratum to: J Fourier Anal Appl DOI 10.1007/s00041-015-9427-9}

After proofreading by the authors was finished, errors were introduced in the references during typesetting as follows:

An incorrect and partial reference was introduced, reading "4. Cambridge tracts in mathematics 120. Cambridge University Press, Cambridge (1996)”. References to this should really point to bibliography item number 8 in the paper.

On the other hand, one item was omitted in the bibliography. Hence, where the paper cites item 8 in its bibliography, it should really point to the following (here numbered as [1]).

\section{References}

1. Duoandikoetxea, J.: Fourier analysis. Transl. from the Spanish and revised by David Cruz-Uribe. Graduate Studies in Mathematics (English), vol. 29. American Mathematical Society, Providence, RI (2001)

Communicated by Hans G. Feichtinger.

The online version of the original article can be found under doi:10.1007/s00041-015-9427-9.

Marcel Rosenthal

marcel.rosenthal@uni-jena.de

Hans-Jürgen Schmeisser

mhj@uni-jena.de

1 Mathematisches Institut, Friedrich-Schiller-Universität Jena, 07737 Jena, Germany 